\section{Upregulation of cardiac NO/NOS system during short-term hypoxia and the subsequent reoxygenation period}

\author{
A. Rus, M.L. Del Moral, F. Molina, \\ M.A. Peinado \\ Department of Experimental Biology, \\ University of Jaén, Spain
}

\section{Abstract}

Hypoxia/reoxygenation (H/R) reportedly influences nitric oxide (NO) production and NO synthase (NOS) expression in the heart. Nonetheless, a number of works have shown controversial results regarding the changes that the cardiac NO/NOS system undergoes under such situations. Therefore, this study aims to clarify the behaviour of this system in the hypoxic heart by investigating seven different reoxygenation times. Wistar rats were submitted to $\mathrm{H} / \mathrm{R}$ (hypoxia for $30 \mathrm{~min}$; reoxygenation of $0,2,12,24,48,72 \mathrm{~h}$, and 5 days) in a novel approach to address the events provoked by assaults under such circumstances. Endothelial and inducible NOS (eNOS and iNOS) mRNA and protein expression, as well as enzymatic activity and enzyme location were determined. NO levels were indirectly quantified as nitrate/nitrite, and other $\mathrm{S}$ nitroso compounds (NOx), which would act as NO-storage molecules. The results showed a significant increase in eNOS mRNA, protein and activity, as well as in NOx levels immediately after hypoxia, while iNOS protein and activity were induced throughout the reoxygenation period. These findings indicate that, not only short-term hypoxia, but also the subsequent reoxygenation period upregulate cardiac NO/NOS system until at least 5 days after the hypoxic stimulus, implying major involvement of this system in the changes occurring in the heart in response to $\mathrm{H} / \mathrm{R}$.

\section{Introduction}

Hypoxia is one of the most frequently encountered types of stress in health and disease. The heart may be submitted to hypoxia in many circumstances, including ischaemia, haemorrhage, pulmonary diseases, cardiac arrest, exposure to high altitude, and other cardiovascular problems. It has been suggested that nitric oxide (NO) plays a critical role in modulating cardiac function during hypoxia. ${ }^{1}$
NO is synthesised from L-arginine by a group of hemoproteins known as NO synthases (NOS). Three NOS isoforms have been classically identified: ${ }^{2}$ endothelial NOS (eNOS), inducible NOS (iNOS) and neuronal NOS (nNOS). Whereas eNOS and nNOS are usually constitutively expressed under physiological conditions, iNOS can be induced by certain stimuli, including hypoxia, chemokines, and cytokines. ${ }^{3,4}$ Most of the NOS activity in the heart corresponds to eNOS, which is located in the vascular endothelium within the myocardium, as well as in the cardiomyocytes. ${ }^{5}$ By contrast, nNOS appears much less prominent, being located in scattered nerves and ganglion cells. ${ }^{6}$ Meanwhile, iNOS can be induced in macrophages, endothelial cells, and cardiomyocytes $^{5-7}$ in response to some stimuli, such as hypoxia. ${ }^{4,8}$

The study of NOS and the role of NO during myocardial ischaemia/reperfusion has become one of the fastest growing fields in basic cardiovascular research in recent years. However, the study of the cardiac NO/NOS system under hypoxia/reoxygenation has been scarcely explored, despite the great interest of this topic, which has been previously taken into account by our group in the central nervous system, ${ }^{9-11}$ the lung, ${ }^{12-15}$ and the heart. ${ }^{16}$ It has been reported that hypoxia/reoxygenation may influence NO production and tissue concentration, as well as eNOS and iNOS expression in the heart. ${ }^{1,17}$ Nonetheless, a number of works in the literature have shown controversial results regarding the changes that the cardiac NO/NOS system undergoes under hypoxia/ reoxygenation.,18-25 Hypoxia resulting from ischaemia, haemorrhage or other cardiovascular problems is a common scenario in the clinical practice of medicine, making the search for useful remedies an essential effort. Thus, the clarification of the behaviour of the cardiac NO/NOS system under hypoxia/reoxygenation is critical, since it could open the possibility of future studies to design novel therapies for hypoxia problems based on NO-pharmacology. The study of the reoxygenation period is not only quite novel, but also an essential way to deal with these types of studies, since reoxygenation generally does not completely reverse hypoxia-induced changes.

\section{Materials and Methods}

\section{Animals}

The study was performed on mature adult (4-5 months old) male albino Wistar rats kept under standard conditions of light and temperature and allowed ad libitum access to food and water. All the experiments were conducted according to E.U. guidelines on the use of ani-
Correspondence: Alma Rus, Department of Experimental Biology (Building B-3), University of Jaén,Campus Las Lagunillas s/n, 23071 Jaén, Spain.

Tel. +34.953.212761- Fax: +34.953.211875.

E-mail:mrus@ujaen.es

Key words: hypoxia, nitric oxide, nitric oxide synthase, reoxygenation.

Conflict of interest: the authors declare no conflict of interest.

Acknowledgements: the authors wish to thank Rafael Lomas for his statistic assistance, and David Nesbitt for his editorial help with the English version of the manuscript.

This work was supported by "MCyT" (BIO 20000405-P4-05; SAF2003-04398-C02-02) and Junta de Andalucía (CVI-0184).

Received for publication: 27 January 2011. Accepted for publication: 8 April 2011.

This work is licensed under a Creative Commons Attribution NonCommercial 3.0 License (CC BYNC 3.0).

CC Copyright A. Rus et al., 2011

Licensee PAGEPress, Italy

European Journal of Histochemistry 2011; 55:e17 doi:10.4081/ejh.2011.e17

mals for biochemical research (86/609/EU), as well as to the Guiding Principles in the Care and Use of Laboratory Animals, endorsed by the American Physiological Society.

\section{Experimental model}

The acute hypobaric hypoxia was carried out as previously published by our group..$^{10,26}$ Briefly, animals were placed in a chamber in which the air pressure was controlled by means of a continuous vacuum pump and an adjustable inflow valve. Hypoxia was induced by downregulating the environmental $0_{2}$ pressure to a final barometric pressure of $225 \mathrm{~mm}$ $\mathrm{Hg}$, resulting in a $48 \mathrm{~mm} \mathrm{Hg} \mathrm{O}_{2}$ partial pressure $\left(\mathrm{pO}_{2}\right)$. These conditions were maintained for $30 \mathrm{~min}$. The ascent and descent speeds were kept at less than $1000 \mathrm{feet} / \mathrm{min}$, with duration of 30 min each (Figure 1). After the hypoxia period, animals were kept under normobaric normoxic conditions for different reoxygenation times $(0,2,12,24,48,72 \mathrm{~h}$, and 5 days), and then sacrificed. Control animals were sacrificed after being maintained for 30 min in the chamber under normobaric normoxic conditions. A total of 40 albino Wistar rats were used for the biochemical experiments (5 animals per experimental group). The rats were sacrificed by cervical dislocation and the hearts were immediately removed, rinsed in saline solution, and stored at $-80^{\circ} \mathrm{C}$ until used. Further 40 rats were used for 
immunohistochemistry (5 animals per experimental group). The rats were anaesthetized with Ketolar (1 mL/250 g weight, Parke Davis, New York, NY, USA) by intraperitoneal injection and perfused in each reoxygenation period. Then, the hearts were removed, rinsed in saline solution and fixed.

\section{Quantitative Real-Time polymerase chain reaction}

Total heart RNA, isolated using Trizol reagent (Invitrogen, Carlsbad, CA, USA) according to the manufacturer's instructions, was used for cDNA synthesis with Superscript reverse transcriptase, as well according to the manufacturer's instructions. Quantitative Real-Time polymerase chain reaction (RTPCR) was carried out in the Mx3005PTM (Stratagene, Cedar Creek, TX, USA) thermal cycler. Hypoxia inducible factor-1 $\beta$ (HIF-1 $\beta$ ) was used as the reference gene, since it is constitutively expressed under normoxic and hypoxic situations. ${ }^{27,28}$ The design of the primers was performed using the software Primer 3. Sequences of used primers (forward, reverse) were ATGGATGAGCCAACTCAAGG and GGCTGCAGTCCTTTGATCTC for eNOS; AAGAG TTCCCATCATTGCGT and TCCTCAACCTGCTCCTCACT for iNOS; and GCAGGATCAGAACACAGCAA and ATGGTTACGGGAGGGGTAAG for HIF-1 $\beta$.

Amplification conditions consist of initial denaturing $\left(95^{\circ} \mathrm{C}, 10 \mathrm{~min}\right)$, followed by 45 cycles of: denaturing $\left(95^{\circ} \mathrm{C}, 30 \mathrm{~s}\right)$, primer annealing $\left(60^{\circ} \mathrm{C}, 30 \mathrm{~s}\right)$, elongation $\left(72^{\circ} \mathrm{C}, 30\right.$ $\mathrm{s})$; and later $95^{\circ} \mathrm{C}(1 \mathrm{~min}), 55^{\circ} \mathrm{C}(30 \mathrm{~s})$, and $95^{\circ} \mathrm{C}(30 \mathrm{~s})$. All experiments were performed in triplicates, and the values were used to calculate the ratio of NOS to HIF-1 $\beta$, with a value of 1 used as the control (calibrator). The relative expression of NOS was calculated by the $2[-\Delta \Delta \mathrm{C}(\mathrm{T})]$ method. $^{29}$

\section{Western blot analysis}

For Western blot analysis, equal amounts of denatured heart total-protein extracts were loaded and separated in 7.5\% SDS-polyacrylamide gel. Proteins in the gel were transferred to a PVDF membrane (Amersham Pharmacia Biotech, Buckinghamshire, UK) and then blocked. Monoclonal antibodies to eNOS (1/800, BD Transduction Lab., Franklin Lakes, NJ USA), iNOS (1/700, BD Transduction Lab.), and $\beta$-actin (Sigma-Aldrich, St. Louis, MD, USA), as internal control, were used to detect the respective proteins. Antibody reaction was revealed by chemiluminescence detection following the manufacturer's recommendations (ECL kit, Amersham Corp.).

\section{${ }^{14} \mathrm{C}$-L-Citrulline assay}

The enzymatic activity of the NOS isoforms was measured in heart homogenates as the rate of conversion of radiolabelled $\mathrm{L}$-arginine to L-citrulline in the assay described by Radomski. ${ }^{30}$ Briefly, after homogenization and centrifugation, the samples were incubated at $37^{\circ} \mathrm{C}$ with $\left[\mathrm{U}^{14} \mathrm{C}\right]$-L-arginine (Amersham Biosciences) in assay buffer $\left(50 \mathrm{mM} \mathrm{KH}_{2} \mathrm{PO}_{4} ; 1\right.$ $\mathrm{mM} \mathrm{MgCl}_{2} ; 0.2 \mathrm{mM} \mathrm{CaCl}$; $50 \mathrm{mM}$ L-valine; 1 mM L-citrulline; $20 \mu \mathrm{M}$ L-arginine; $0.1 \mathrm{mM}$ $\mathrm{NADPH} ; 10 \mu \mathrm{M} \mathrm{BH}_{4} ; 0.1 \mathrm{M}$ FAD; 0.1 M FMN, and dithiotreitol $5 \mathrm{mM}$ in Tris- $\mathrm{HCl}$ ) (SigmaAldrich). The addition of $1 \mathrm{mM}$ L-NAME (Sigma-Aldrich) was used to detect the reaction background, while the addition of $2 \mathrm{mM}$ ethylene glycol-bis $\beta$-aminoethyl ether (Sigma-Aldrich), a $\mathrm{Ca}^{2+}$-chelator, was used to differentiate between $\mathrm{Ca}^{2+}$-dependent (eNOS) and $\mathrm{Ca}^{2+}$-independent (iNOS) activities.

After 20 min of incubation, the reaction was stopped by adding Dowex 50W-X 8-400 ionexchange resin (Sigma-Aldrich), and the radioactivity in the supernatant was determined in a liquid-scintillation counter (Wallac 1410, Pharmacia).

\section{Immunohistochemistry}

Hearts were fixed with paraformaldehyde $4 \%$ for $18 \mathrm{~h}$, and then embedded in paraffin (Paraplast Extra, Tyco Healthcare, Mansfield, MA, USA). Sections were incubated for $30 \mathrm{~min}$ with $10 \%$ serum of the animal in which the secondary antibody was produced. Afterwards, they were incubated first with diluted monoclonal anti-iNOS (1:600) and anti-eNOS (1:400) antibodies (BD Transduction Lab.) in PBS overnight at $4^{\circ} \mathrm{C}$, and later with a biotinylated secondary antibody (1:450; Pierce Biotechnology, Inc., Rockford, IL, USA) followed by peroxidase-linked ABC. The peroxidase activity was demonstrated following the nickel-enhanced diamino-benzidine procedure.${ }^{31}$ Sections were mounted on slides, dehydrated, and covered using DPX. Controls for background staining were performed by replacing the primary antibody with $\mathrm{PBS}$.

\section{NO measurement}

The reaction of NO with ozone results in light emission, and this light (emitted in proportion to the NO concentration) is the basis for one of the most accurate NO assays available. ${ }^{32,33} \mathrm{NO}$ production was indirectly quantified by measuring nitrate/nitrite and S-nitroso compounds (NOx) using an ozone chemiluminescence-based method. For this technique, hearts were homogenized in PBS with protease inhibitors. Homogenates were then sonicated, centrifuged, and deproteinized with $\mathrm{NaOH} 0.8 \mathrm{~N}$ and $\mathrm{ZnSO}_{4} 16 \%$ solutions. The total amount of NOx was determined by a modification $^{26}$ of the procedure described by Braman and Hendrix ${ }^{34}$ using a NO analyser (NOA $^{\mathrm{TM}}$ 280i Sievers Instruments, Boulder, CO, USA). A saturated solution of vanadium chloride (VCl3) in $1 \mathrm{M} \mathrm{HCl}$ was added to the nitrogen-bubbled purge vessel fitted with a cold-water condenser and a water jacket to permit heating of the reagent to $90^{\circ} \mathrm{C}$, using a circulating bath. $\mathrm{HCl}$ vapours were removed by a gas bubbler containing $1 \mathrm{M} \mathrm{NaOH}$. The gas-flow rate in the detector was controlled by a needle valve adjusted to yield a constant pressure. Once the detector signal was stabilized, samples were injected into the purge vessel to react with the reagent, converting $\mathrm{NOx}$ to $\mathrm{NO}$, which was then detected by ozone-induced chemiluminescence. NOx concentrations were calculated by comparison with standard solutions of sodium nitrate. Final NOx values were referred to the total protein concentration in the initial extracts.

\section{Statistical analysis}

Data were expressed as mean \pm SD (standard deviation). The statistical treatment to evaluate significant differences between groups was performed with SPSS 15.0 software. The data followed a normal distribution (tested with Kolmogorov-Smirnov test) and the principle of homoscedasticity of variances (tested with Levene test), and were tested by a one-way ANOVA. The degree of statistical significance was established by applying an unpaired Student's t-test to compare differences between means. The statistically significant differences

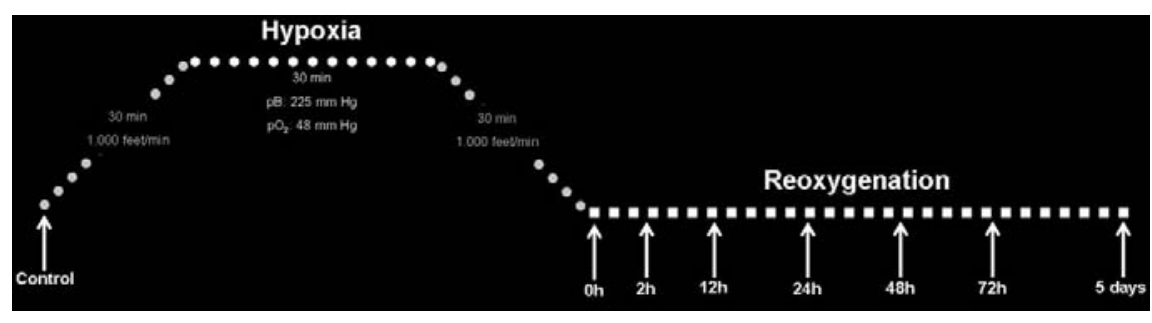

Figure 1. Experimental model of hypoxia/reoxygenation. 
vs. the control group were expressed as ${ }^{*} \mathrm{P}<0.05 ;{ }^{* *} \mathrm{P}<0.02 ;{ }^{* * *} \mathrm{P}<0.01 ;{ }^{* * * *} \mathrm{P}<0.001$.

\section{Results}

\section{NOS mRNA expression}

The quantitative analysis of eNOS mRNA expression (Figure 2A) showed a statistically significant increase at $0 \mathrm{~h}$ post-hypoxia $(\mathrm{P}<0.02)$. On the other hand, iNOS mRNA levels (Figure 2B) significantly rose at the onset of reoxygenation $(0 \mathrm{~h}: \mathrm{P}<0.001)$.

\section{NOS protein expression}

The eNOS protein expression (140-kDa) significantly increased from $0 \mathrm{~h}$ to $12 \mathrm{~h}$ posthypoxia ( 0 h: $\mathrm{P}<0.01 ; 2 \mathrm{~h}: \mathrm{P}<0.001 ; 12 \mathrm{~h}$ : $\mathrm{P}<0.001)$. From this time point on, eNOS expression appeared to recover to baseline levels, which were maintained until 5 days of reoxygenation (Figure 3A). It was barely possible to detect iNOS protein in the heart of control animals (Figure 3B). Nevertheless, this NOS isoform $(130-\mathrm{kDa})$ was induced in all the experimental groups after hypoxia $(0 \mathrm{~h}, 2 \mathrm{~h}, 12$ h, 24 h, 48 h, 72 h, and 5 days: $\mathrm{P}<0.001$ ).

\section{NOS activity}

The constitutive NOS enzymatic activity significantly rose at $0 \mathrm{~h}(\mathrm{P}<0.05), 2 \mathrm{~h}(\mathrm{P}<0.001)$ and $12 \mathrm{~h}(\mathrm{P}<0.001)$ of reoxygenation (Figure $4 \mathrm{~A})$. On the other hand, iNOS activity significantly augmented throughout the post-hypoxia period ( $0 \mathrm{~h}: \mathrm{p}<0.05 ; 2 \mathrm{~h}, 12 \mathrm{~h}, 24 \mathrm{~h}: \mathrm{p}<0.001 ; 48$ h, 72 h, 5 days: $\mathrm{P}<0.05$ ) (Figure 4B).

\section{NOS immunohistochemistry}

In all the experimental groups, eNOS immunoreactivity was detected in vascular endothelial cells and cardiomyocytes (Figure 5). As reflected in Figure 6, no iNOS immunoreactivity could be detected in the control group. Nevertheless, iNOS-positive staining appeared in the myocardium after hypoxia (0 h, 12 h, 5 days). Here, we show only the most representative images of eNOS and iNOS tissue location, corresponding to 4 of the 8 experimental groups. Magnification of eNOS and iNOS positive structures is shown in Figure 7 , in order to allow easily identifying eNOS and iNOS immunoreactive cells.

\section{NO production}

Figure 8 shows the determinations of nitrate/nitrite and other S-nitroso compounds (NOx) in the different experimental groups NOx levels significantly rose at $0 \mathrm{~h}$ post-hypoxia $(\mathrm{P}<0.001)$ in the heart homogenates. After rising initially, NOx levels began to fall until reaching values even lower to those of the control group after $5 \mathrm{~d}$ of reoxygenation.

\section{Discussion}

The study of cardiac hypoxia-associated
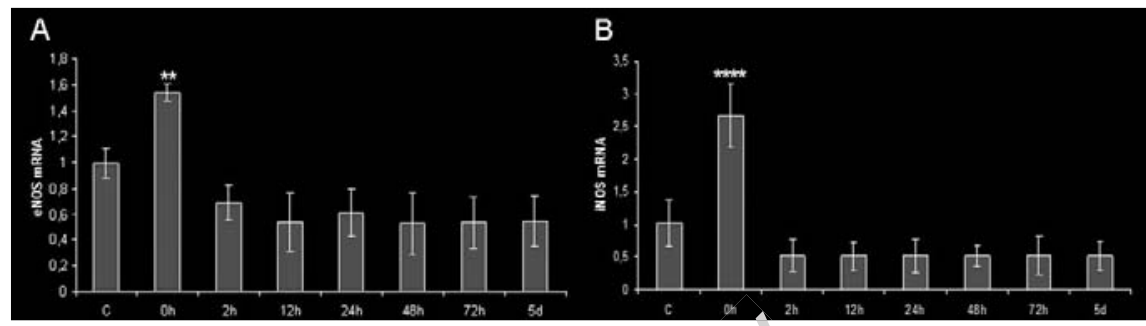

Figure 2. Effect of hypoxia/reoxygenation on NOS (nitric oxide synthase) isoforms mRNA expression in heart of adult rats. Real-time PCR analysis of eNOS (A) and iNOS (B). Experimental groups: control (C), and 0, 2, 12, 24, 48, $72 \mathrm{~h}$, and 5 days (5d) post-hypoxia. Results were expressed as arbitrary units. Results are mean values of three independent experiments and five animals per group. The statistically significant differences vs. the control group were expressed as ${ }^{*} \mathrm{P}<0.05$; ${ }^{* *} \mathrm{P}<0.02$; ${ }^{* * *} \mathrm{P}<0.01$; ${ }^{* * *} \mathrm{P}<0.001$.

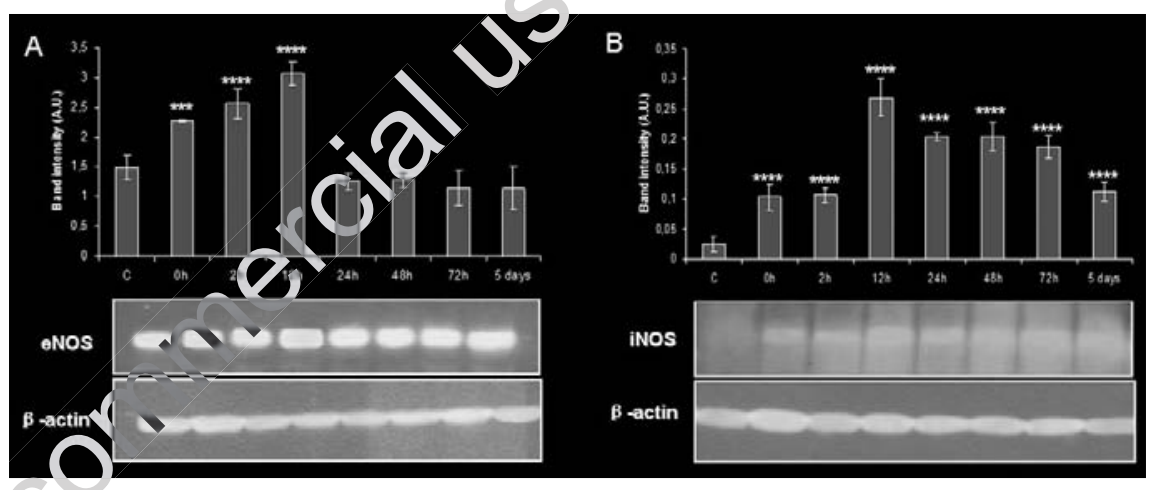

Figure 3. Effect of hypoxia/reoxygenation on NOS (nitric oxide synthase) isoforms protein expression in heart of adult rats. Western blot analysis of eNOS (A) and iNOS (B). Top panels: densitometric quantification of NOS isoforms in the different experimental groups (Control (C), and $0,2,12,24,48,72 \mathrm{~h}$, and 5 days post-hypoxia), expressed as arbitrary units (A.U.). Results are mean values of five independent experiments and five animals per group. Bottom panels: representative autoradiography of the five determinations of the corresponding eNOS and iNOS bands; $\beta$-actin immunodetection was included as a protein-loading control. The statistically significant differences vs. the control group were expressed as ${ }^{*} \mathrm{P}<0.05 ;{ }^{* *} \mathrm{P}<0.02 ;{ }^{* * *} \mathrm{P}<0.01 ;{ }^{* * *} \mathrm{P}<0.001$.
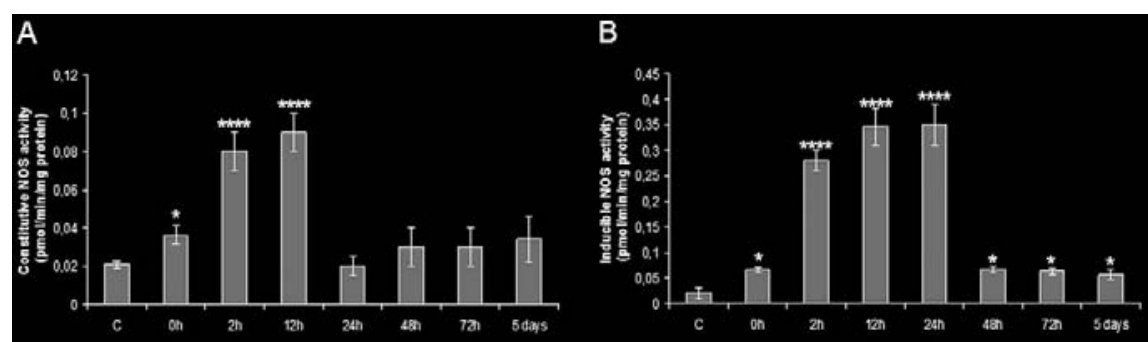

Figure 4. Effect of hypoxia/reoxygenation on NOS (nitric oxide synthase) enzymatic activity in heart of adult rats. ${ }^{14} \mathrm{C}-\mathrm{L}-\mathrm{Citrulline}$ assay for constitutive NOS $(\mathrm{A})$ and inducible NOS (B). Experimental groups: Control (C), and 0, 2, 12, 24, 48, $72 \mathrm{~h}$, and 5 days post-hypoxia. Results were expressed as $\mathrm{pmol} / \mathrm{min} / \mathrm{mg}$ protein. Results are mean values of three independent experiments and five animals per group. The statistically significant differences vs. the control group were expressed as ${ }^{*} \mathbf{P}<0.05 ;{ }^{* *} \mathbf{P}<0.02 ;{ }^{* * *} \mathbf{P}<0.01$; $* * * * \mathbf{P}<\mathbf{0 . 0 0 1}$ 
in the heart. Nonetheless, a number of works have shown controversial results regarding the changes that the cardiac NO/NOS system undergoes under such situations. Hence, the present work aims to clarify the behaviour of this system in the heart submitted to hypoxia/reoxygenation.

Our results show that our model of

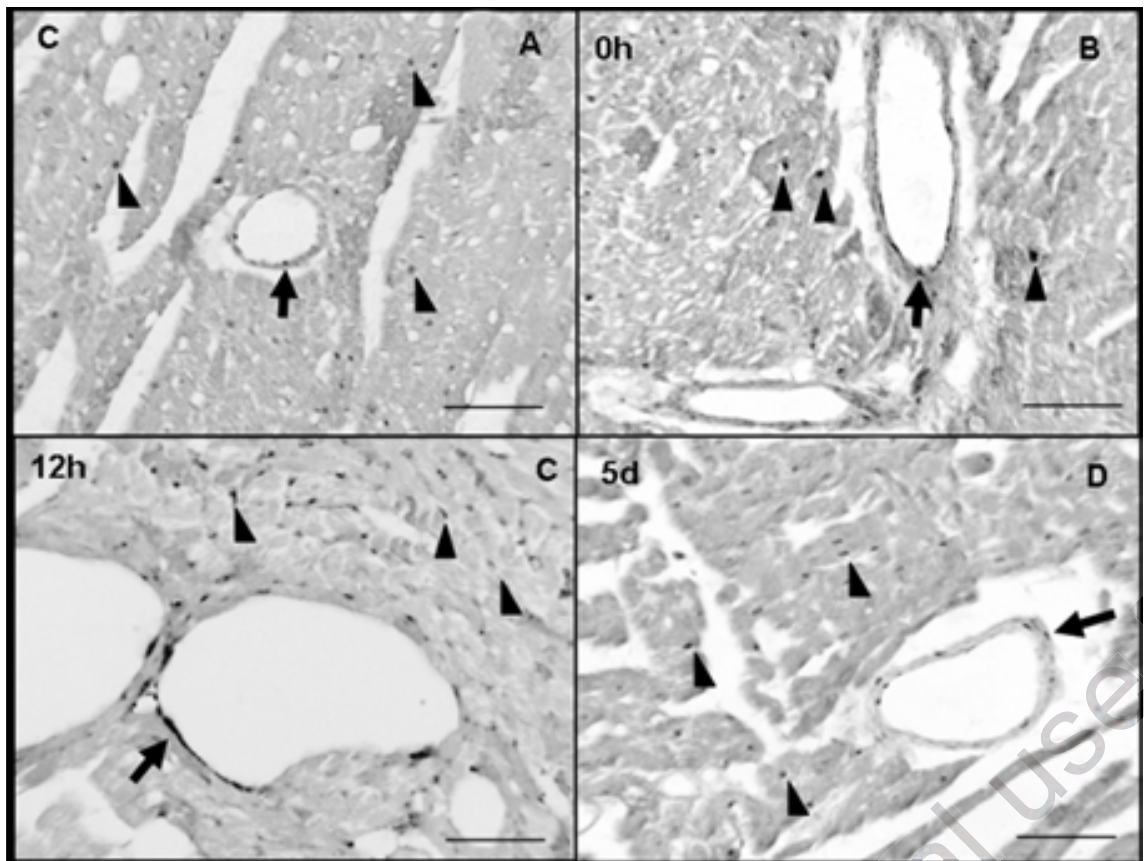

Figure 5. (A-D) Histological sections of rat heart stained for eNOS immunohistochemistry. eNOS immunoreactivity was detected in endothelial cells (arrows) and cardiomyocytes (arrow heads) in all the experimental groups: Control (C), and $0 \mathrm{~h}, 12 \mathrm{~h}$, and 5 days (5d) post-hypoxia. Scale bars: $50 \mu \mathrm{m}$.
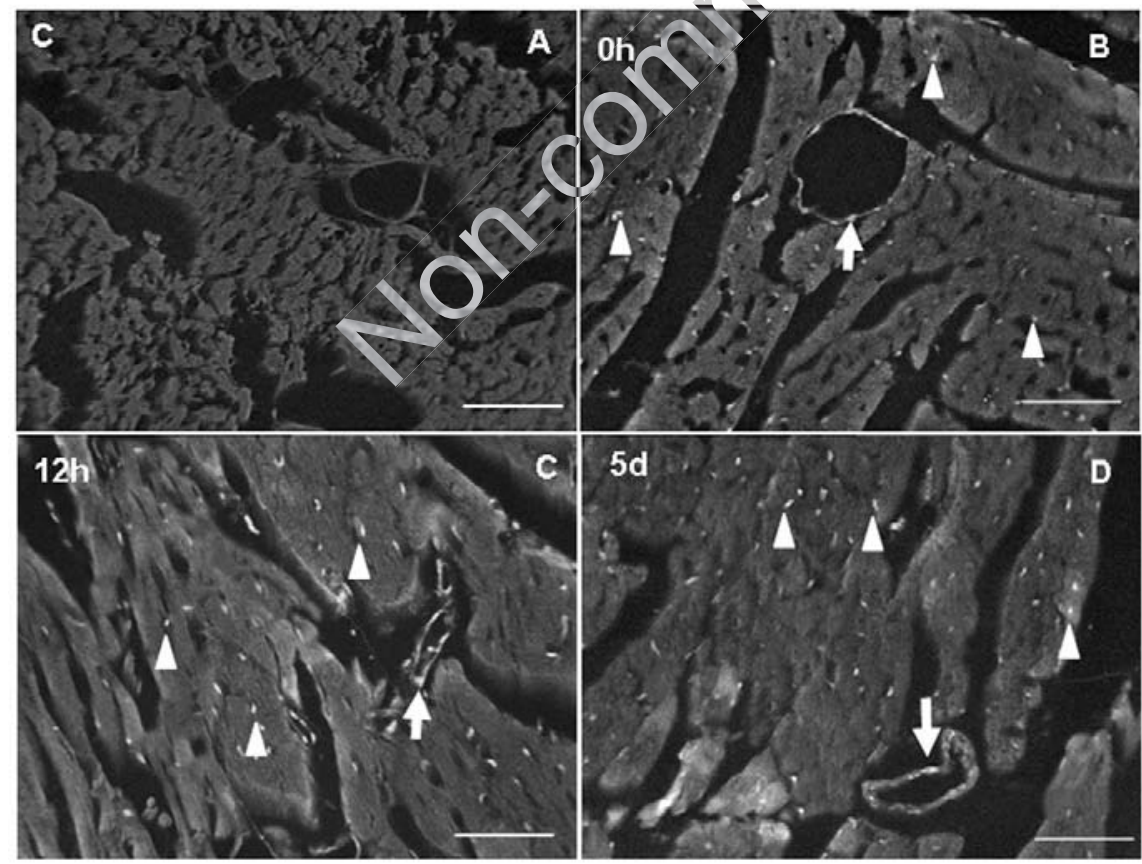

Figure 6. (A-D) Histological sections of rat heart stained for iNOS immunohistochemistry. No iNOS immunoreactivity could be detected in the control group (C). Nevertheless, iNOS-positive staining appeared in endothelial cells (arrows) and cells in myocardium (arrow heads) after hypoxia $(0 \mathrm{~h}, 12 \mathrm{~h}$, and 5 days $(5 \mathrm{~d})$ post-hypoxia). Scale bars: $50 \mu \mathrm{m}$. hypoxia/reoxygenation significantly raised eNOS and iNOS mRNA and protein levels, as well as enzymatic activity at the onset of reoxygenation, implying that $0 \mathrm{~h}$ post-hypoxia is a crucial moment in the changes that the NO/NOS system undergoes during cardiac hypoxia/reoxygenation. We show that after rising initially, mRNA levels begin to fall after the hypoxic stimulus, although the higher protein levels persisted during the reoxygenation period. In this way, the results reflect raised eNOS

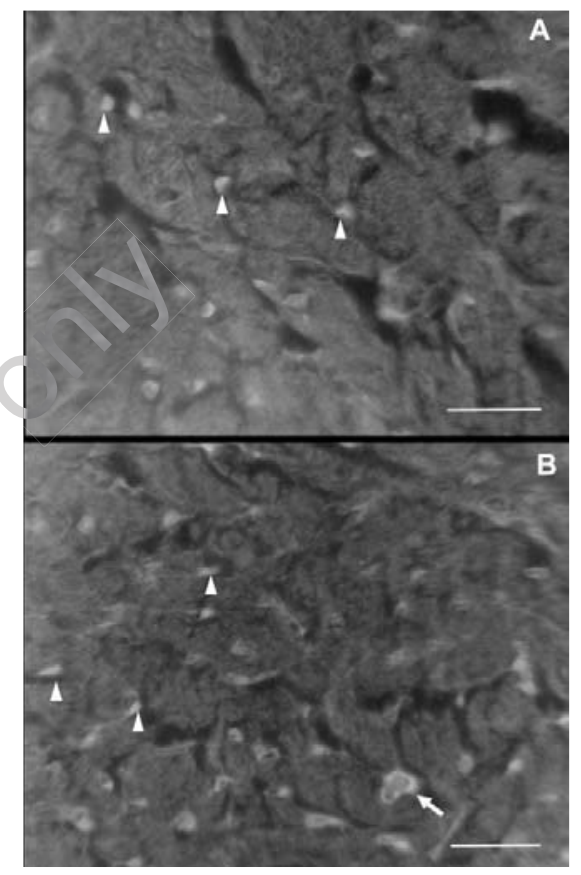

Figure 7. Histological sections of rat heart stained for eNOS (A) and iNOS (B) immunohistochemistry. Magnification of eNOS (A) and iNOS (B) positive structures after $12 \mathrm{~h}$ post-hypoxia (arrows: endothelial cells, arrow heads: cardiomyocytes). Scale bars: $10 \mu \mathrm{m}$.

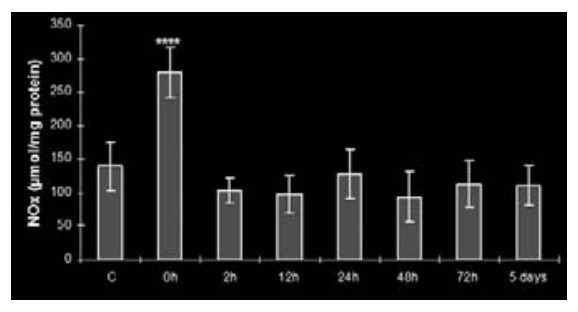

Figure 8. Effect of hypoxia/reoxygenation on nitrate, nitrite, and other $S$-nitroso compounds $(\mathrm{NOx})$ in heart of adult rats. Experimental groups: Control (C), and 0, $2,12,24,48,72 \mathrm{~h}$, and 5 days post-hypoxia. Results were expressed as $\mu \mathrm{mol} / \mathrm{mg}$ protein. Results are mean values of three independent experiments and five animals per group. The statistically significant differences vs. the control group were expressed as $\quad * \mathbf{P}<\mathbf{0 . 0 5} ; \quad{ }^{* *} \mathbf{P}<\mathbf{0 . 0 2} ; \quad{ }^{* * *} \mathbf{P}<\mathbf{0 . 0 1}$; **** $\mathbf{P}<\mathbf{0 . 0 0 1}$. 
mRNA levels at $0 \mathrm{~h}$ post-hypoxia, while the protein increased from $0 \mathrm{~h}$ to $12 \mathrm{~h}$ of reoxygenation. On the other hand, we detected a 2.5 -fold increase in iNOS mRNA immediately after the hypoxic insult, while iNOS protein was induced throughout the reoxygenation period. In fact, numerous pathophysiological stimuli, including hypoxia, have been identified to modulate NOS expression via mechanisms that alter steady-state NOS mRNA levels. These mechanisms involve changes in the rate of NOS gene transcription, as well as alteration of NOS mRNA processing and stability. ${ }^{35,36}$ Our results suggest that hypoxia may boost NOS mRNA levels at the onset of reoxygenation as a cardiac response to hypoxic stress. We show that hypoxia-activated expression of NOS $\mathrm{mRNA}$ at $0 \mathrm{~h}$ fell to physiological levels during the subsequent reoxygenation period, implying that once its function (translation to protein) was concluded, mRNA was degraded until reaching basal values after $2 \mathrm{~h}$ post-hypoxia. Raised mRNA levels are not usually needed for a long time period, since proteins can remain longer in the cells if they are required. In this regard, elevated eNOS and iNOS protein levels have been detected in the later post-hypoxia times, implying an important role for these proteins in the changes occurring during cardiac hypoxia/reoxygenation.

The behaviour of NOS isoforms under hypoxia has long been controversial, probably due to the severity and duration of the hypoxia model, the enormous intrinsic complication of the NO/NOS system regulation, and the species and tissue studied. In agreement with our results, some authors have shown that eNOS increases in the hypoxic heart, ${ }^{19,21}$ whereas other studies have reported that myocardial hypoxia/reoxygenation is associated with a decrease in eNOS. ${ }^{1,22}$ One of the most accepted mechanisms by which hypoxia could increase eNOS expression is based on the fact that hypoxia can activate the transcription of a reporter gene under control of the eNOS 5'flanking region. ${ }^{37}$ In addition, Hoffman et al. suggested that activation of the redox-sensitive activator protein-1 transcription factor during hypoxia might be responsible for the increase in eNOS expression. ${ }^{38}$ Regarding iNOS, while some authors have reported a greater expression in the hypoxic rat heart, ${ }^{7,8,25}$ others have shown that iNOS is substantially downregulated by hypoxia in the ventricles. ${ }^{19}$ Moreover, it has been reported that hypoxia alone has no effect on iNOS gene expression, or protein induction in cardiomyocytes. ${ }^{20}$ The inconsistency of these results concerning eNOS and iNOS expression may be due to differences in the experimental protocol used, or to the cardiac cell types examined. In addition, those studies investigated only the time immediate after hypoxia, not the reoxygenation period, as we do in this work. The most accepted hypothesis to explain how hypoxia increases iNOS expression involves the hypoxia inducible factor-1 (HIF-1), a central component of the oxygen-sensing system that coordinates cellular responses under conditions of decreased oxygen availability. ${ }^{8}$ The iNOS promoter contains a hypoxic responsive element, and HIF-1 could bind this element under hypoxic situations to increase iNOS transcription. ${ }^{39,40}$

There is also great debate concerning the constitutive/inducible character of iNOS in the healthy heart. In this respect, some authors have described inducible NOS in normal cardiac tissue, ${ }^{41,42}$ while others have failed to find iNOS in healthy hearts. ${ }^{6,8}$ We did not succeed in detecting this isoform in histological sections of control rat heart. Contrarily, iNOS immunostaining has been reported in cardiomyocytes, ${ }^{41}$ and the endothelium of coronary vessels ${ }^{42}$ in control rats. Nevertheless, iNOS-positive staining appeared in the myocardium during the post-hypoxia period. Our results have also shown no iNOS protein expression in the control group, although there was a basal mRNA expression. In this regard, human primary cardiomyocytes in cell culture express iNOS mRNA, but no iNOS protein. The inability of the cardiomyocytes to translate iNOS mRNA was correlated with the presence of the 5'- or 3'-UTR of the human iNOS mRNA. ${ }^{43}$ Our findings support the contention that the translation of iNOS mRNA in the healthy heart is not necessary, since there is a basal NO production, derived mainly from eNOS, to maintain the normal blood flow under physiological conditions. Nevertheless, a basal iNOS mRNA expression could be required in emergency conditions for exerting a key role during such situations. In this sense, our results show that after the hypoxic stimulus, iNOS was induced throughout the reoxygenation period, indicating major involvement of this isoform in the changes that occur during cardiac hypoxia/reoxygenation. In fact, in a recent work using the selective iNOS inhibitor $\mathrm{N}$-(3-(aminomethyl)benzyl) acetamidine or $1400 \mathrm{~W}$, we have proposed that iNOS may have a protective effect in the rat heart against hypoxia/reoxygenation injuries, challenging the conventional wisdom that this isoform is deleterious under such conditions. ${ }^{16}$

The constitutive NOS enzymatic activity significantly rose from $0 \mathrm{~h}$ to $12 \mathrm{~h}$ of reoxygenation, coinciding with raised eNOS protein levels. From these data, it may be assumed that the majority of the constitutive NOS activity in the heart corresponds to eNOS, detected in vascular endothelial cells and cardiomyocytes. In this regard, it is well-known that nNOS expression is much less prominent in this organ. ${ }^{6}$ Moreover, it has been reported that hypoxia has no significant impact on cardiac nNOS expression (mRNA and protein). ${ }^{24}$ In short, our results have shown a significant rise in eNOS mRNA, protein and activity, as well as in NOx levels immediately after hypoxia. In addition, eNOS protein levels and activity remained higher until $12 \mathrm{~h}$ of reoxygenation, suggesting an emergency function of cardiac NO/eNOS system at the earliest post-hypoxia times. In this sense, the increased eNOSderived $\mathrm{NO}$ at the onset of reoxygenation may exert a vasodilator effect in order to regulate the blood flow through the hypoxic tissues. On the other hand, iNOS activity was induced throughout the post-hypoxia period, also matching with augmented iNOS protein expression. In agreement, hypoxia/reoxygenation has been reported to markedly increase iNOS activity in cardiomyocytes. ${ }^{1}$ However, the rise in NOS enzymatic activity at the onset of reoxygenation contrasts with other works reporting that during hypoxia, low oxygen tensions can limit NOS activity. ${ }^{44}$ In fact, early studies in humans found that NOS activity varies in direct proportion to oxygen levels. ${ }^{45}$ These controversial results may be due to the different times in which the NOS activity measurements were made. In this work, we determined NOS enzymatic activities after the descent post-hypoxia time (30 min), when oxygen increases progressively until reaching normobaric normoxic levels.

The question whether increased NOS expression leads to higher NO production in vivo is controversial. ${ }^{46}$ Our results indicate that hypoxia/reoxygenation significantly raised NO levels, indirectly quantified by nitrate/nitrite and S-nitroso compounds (NOx), just after the hypoxic stimulus. This result coincides with significantly augmented eNOS and iNOS expression, suggesting that both isoforms would contribute to the higher NOx levels at the onset of reoxygenation. However, it is feasible that this greater NO production could also be supported by the NO-storage molecules. These molecules constitute a NOS-independent generation of NO in vivo, and can scavenge or supply NO under emergency conditions. ${ }^{47-49}$ In agreement with our results, some previous works demonstrated that hypoxia increased NO in cardiomyocytes, ${ }^{18,22,25}$ and in cardiac microvessel endothelial cells..$^{22,25}$ On the opposite, other authors found that hypoxia did not change NO production in cardiomyocytes. ${ }^{20}$ The reason for the variability in NO levels in these studies is unclear, but may reflect differences in the cardiac cell types analysed, the different experimental model of hypoxia used, or the duration and severity of the hypoxic exposures. Additionally, these studies examined only the onset of reoxygenation, not the post-hypoxia period, as we do in this work. Interestedly, our 
results also show a non-significant decrease in NOx levels at the later reoxygenation times, despite that NOS activity and expression were enhanced. These unexpected results could be explained in part taking into account that eNOS protein levels and activity fell after $12 \mathrm{~h}$ of reoxygenation until reaching physiological levels. Also iNOS protein expression begin to decrease after $12 \mathrm{~h}$ post-hypoxia, as well as the enzymatic activity, suggesting that the involvement of both NOS isoforms in the heart during the final reoxygenation times may be no longer needed. Additionally, the intense NO storage occurring in the vascular wall, which could mask a portion of NO, needs to be considered. ${ }^{50}$ In this regard, as mentioned above, NO can be stored in the form of haemoglobin in red blood cells, nitrosoglutathione, dinitrosyl iron complexes or S-nitrosothiols, and can subsequently be released from these complexes. Furthermore, it is well known that the reoxygenation of the hypoxic cardiac tissue is characterized by an increase in reactive oxygen species (ROS) and reactive nitrogen species (RNS), resulting in widespread lipid peroxidation, protein oxidative and nitrosative modifications, and cellular apoptosis and necrosis. ${ }^{51}$ Peroxynitrite, formed by the reaction of NO and superoxide, is a ROS and RNS that can alter protein function by nitrating phenolic rings, including tyrosine, to create nitrotyrosines. ${ }^{52}$ In this way, it is also worth mentioning that a part of NO could derive in protein nitration throughout the reoxygenation period in the hypoxic heart. Indeed, we have recently reported that our model of hypoxia/reoxygenation boosted the levels of nitrotyrosine-modified proteins in the rat heart during all the post-hypoxia period, especially at $12 \mathrm{~h}^{16}$

All these findings indicate that hypoxia/ reoxygenation processes alter NO levels, as well as eNOS and iNOS expression and activity in the rat heart. We have identified a pattern of NOS regulation, reflecting that these two NOS isoforms are upregulated in this organ, not only under short-term hypoxia, but also during the subsequent reoxygenation period. Given the multiple actions of NO on ion channel activation, regulation of intracellular calcium, phosphorylation of contractile proteins, and induction of apoptotic mechanisms, ${ }^{53-56}$ NOS-derived NO would be expected to have an important physiologic role in the hypoxic rat heart. In this sense, it could be proposed that just after the hypoxic stimulus, NOS-derived NO levels rise to exert a vasodilator effect in order to regulate the maintenance of blood flow through the hypoxic tissues. Thus, all the changes that the NO/NOS system undergoes during hypoxia/reoxygenation could be involved in the adaptation of the heart to such situations. It is noteworthy that all the parameters analysed increased at the onset of reoxy- genation, implying a crucial moment in the changes occurring in the heart in response to hypoxia/reoxygenation. Moreover, the study of the subsequent reoxygenation period reflects changes in the NO/NOS system until 5 days after hypoxia, showing that reoxygenation really does not completely reverse hypoxiainduced changes. These findings reveal the enormous intrinsic complication of the NO/NOS system regulation under cardiac hypoxia/ reoxygenation. This is a necessary study revealing the behaviour of the NO/NOS system under hypoxia and the later reoxygenation period in the heart, as the basis for further research on this field. In this way, we have previously investigated the changes in the NO/NOS system during such situations in the rat lung, showing that eNOS increased only at the onset of reoxygenation, while iNOS augmented at the final post-hypoxia times. Moreover, dissimilar to what happens in the heart, the normoxic lung showed an iNOS baseline expression. ${ }^{12}$ Therefore, the present work confirms that the changes of NO/NOS system during hypoxia/reoxygenation depends directly on the organ involved. In conclusion, these data taken all together support the idea of regional variability in NO/NOS system expression during systemic hypoxia.

\section{References}

1. Chen H, Li D, Saldeen T, Mehta JL. TGFbeta(1) modulates NOS expression and phosphorylation of $\mathrm{Akt} / \mathrm{PKB}$ in rat myocytes exposed to hypoxia-reoxygenation. Am J Physiol Heart Circ Physiol 2001;281:H1035-9.

2. Förstermann U, Schmidt HH, Pollock JS, Sheng H, Mitchell JA, Warner TD, et al. Isoforms of nitric oxide synthase. Characterization and purification from different cell types. Biochem Pharmacol 1991;42:1849-57.

3. Moncada S, Higgs A. The L-arginine-nitric oxide pathway. N Engl J Med 1993;329: 2002-12.

4. Ricciardolo FL, Sterk PJ, Gaston B, Folkerts G. Nitric oxide in health and disease of the respiratory system. Physiol Rev 2004;84: 731-65.

5. Kelly RA, Balligand JL, Smith TW. Nitric oxide and cardiac function. Circ Res 1996;79:363-80.

6. Ursell PC, Mayes M. Anatomic distribution of nitric oxide synthase in the heart. Int $\mathrm{J}$ Cardiol 1995;50:217-23.

7. Grilli A, De Lutiis MA, Patruno A, Speranza L, Cataldi A, Centurione L, et al. Effect of chronic hypoxia on inducible nitric oxide synthase expression in rat myocardial tis- sue. Exp Biol Med (Maywood) 2003; 228:935-42.

8. Jung F, Palmer LA, Zhou N, Johns RA. Hypoxic regulation of inducible nitric oxide synthase via hypoxia inducible factor-1 in cardiac myocytes. Circ Res 2000; 18;86:319-25.

9 Del Moral ML, Esteban FJ, Hernández R, Blanco S, Molina FJ, Martínez-Lara E, et al. Immunohistochemistry of neuronal nitric oxide synthase and protein nitration in the striatum of the aged rat. Microsc Res Tech 2004;64:304-11.

10. Martínez-Romero R, Cañuelo A, MartínezLara E, Hernández R, Del Moral ML, Pedrosa JA, et al. Aging affects but does not eliminate the enzymatic antioxidative response to hypoxia/reoxygenation in cerebral cortex. Exp Gerontol 2006;41:2531.

11. Cañuelo A, Siles E, Martínez-Romero R, Peinado MA MA, Martínez-Lara E. The nitric oxide system response to hypoxia/ reoxygenation in the aged cerebral cortex. Exp Gerontol 2007;42:1137-45.

12. Rus A, Peinado MA, Castro L, Del Moral ML. Lung eNOS and iNOS are reoxygenation time-dependent upregulated after acute hypoxia. Anat Rec (Hoboken) 2010;293: 1089-98.

13. Rus A, Molina F, Peinado MA, Del Moral Ml. Endogenous nitric oxide can act as beneficial or deleterious in the hypoxic lung depending on the reoxygenation time. Anat Rec (Hoboken) 2010;293:2193-201.

14. Rus A, Molina F, Peinado MA, Del Moral Ml. Endothelial NOS-derived nitric oxide prevents injury resulting from reoxygenation in the hypoxic lung. Free Radic Res 2010;44:1027-35.

15. Rus A, Castro L, Del Moral ML, Peinado MA. Inducible NOS inhibitor 1400W reduces hypoxia/reoxygenation injury in rat lung. Redox Rep 2010;15:169-78.

16. Rus A, Del Moral ML, Molina F, Peinado MA. Does inducible NOS have a protective role against hypoxia/reoxygenation injury in rat heart? Cardiovasc Pathol 2011;20: e17-25.

17. Manukhina EB, Downey HF, Mallet RT. Role of nitric oxide in cardiovascular adaptation to intermittent hypoxia. Exp Biol Med (Maywood) 2006; 231:343-65.

18. Kitakaze M, Node K, Komamura K, Minamino $\mathrm{T}$, Inoue $\mathrm{M}$, Hori $\mathrm{M}$, et al. Evidence for nitric oxide generation in the cardiomyocytes: its augmentation by hypoxia. J Mol Cell Cardiol 1995; 27:214954.

19 Gess B, Schricker K, Pfeifer M, Kurtz A. Acute hypoxia upregulates NOS gene expression in rats. Am J Physiol 1997;273: R905-10. 
20. Kacimi R, Long CS, Karliner JS. Chronic hypoxia modulates the interleukin-1betastimulated inducible nitric oxide synthase pathway in cardiac myocytes. Circulation 1997;96:1937-43.

21. Felaco M, Grilli A, Gorbunov N, Di Napoli P, De Lutiis MA, Di Giulio $C$, et al. Endothelial NOS expression and ischemia-reperfusion in isolated working rat heart from hypoxic and hyperoxic conditions. Biochim Biophys Acta 2000;1524: 203-11.

22. Strijdom H, Jacobs S, Hattingh S, Page C, Lochner A. Nitric oxide production is higher in rat cardiac microvessel endothelial cells than ventricular cardiomyocytes in baseline and hypoxic conditions: a comparative study. FASEB J 2006;20:314-6.

23. Ryou MG, Sun J, Oguayo KN, Manukhina EB, Downey HF, Mallet RT. Hypoxic conditioning suppresses nitric oxide production upon myocardial reperfusion. Exp Biol Med (Maywood) 2008;233:766-74.

24. Thompson L, Dong Y, Evans L. Chronic hypoxia increases inducible NOS-derived nitric oxide in fetal guinea pig hearts. Pediatr Res 2009;65:188-92.

25. Strijdom H, Friedrich SO, Hattingh S, Chamane N, Lochner A. Hypoxia-induced regulation of nitric oxide synthase in cardiac endothelial cells and myocytes and the role of the PI3-K/PKB pathway. Mol Cell Biochem 2009;321:23-35.

26. Lopez-Ramos JC, Martinez-Romero R, Molina F, Cañuelo A, Martínez-Lara E, Siles E, et al. Evidence of a decrease in nitric oxide-storage molecules following acute hypoxia and/or hypobaria, by means of chemiluminescence analysis. Nitric 0xide 2005;13:62-7.

27. Semenza GL. HIF-1 and mechanisms of hypoxia sensing. Curr Opin Cell Biol 2001;13:167-71.

28. Sharp FR, Ran R, Lu A, Tang Y, Strauss KI, Glass T, et al. Hypoxic preconditioning protects against ischemic brain injury. NeuroRx 2004;1:26-35.

29. Li H, Witte K, August M, Brausch I, GodtelArmbrust U, Habermeier A, et al. Reversal of endothelial nitric oxide synthase uncoupling and up-regulation of endothelial nitric oxide synthase expression lowers blood pressure in hypertensive rats. J Am Coll Cardiol 2006;47:2536-44.

30. Radomski MW, Vallance P, Whitley G, Foxwell N, Moncada S. Platelet adhesion to human vascular endothelium is modulated by constitutive and cytokine induced nitric oxide. Cardiovasc Res 1993;27:1380-2.

31. Shu SY, Ju G, Fan LZ. The glucose oxidaseDAB-nickel method in peroxidise histo- chemistry of the nervous system. Neurosci Lett 1988;85:169-71.

32. Laitinen J, Liesivuori J, Linnainmaa M, Kalliokoski P. Evaluation of monitoring methods for nitrogen oxides. Ann Occup Hyg 1993;37:307-14.

33. Fontijn A, Sabadell AJ, Ronco RJ. Homogenous chemiluminiscent measurement of nitric oxide with ozone. Implications for continuous selective monitoring of gaseous air pollutants. Anal Chem 1997;42:575-9.

34. Braman RS, Hendrix SA. Nanogram nitrite and nitrate determination in environmental and biological materials by vanadium (III) reduction with chemiluminescence detection. Anal Chem 1989;61:2715-8.

35. Kleinert H, Pautz A, Linker K, Schwarz PM. Regulation of the expression of inducible nitric oxide synthase. Eur J Pharmacol 2004;500:255-66. Review.

36. Searles CD. Transcriptional and posttranscriptional regulation of endothelial nitric oxide synthase expression. Am J Physiol Cell Physiol 2006;291:C803-16.

37. Arnet UA, Mcmillan A, Dinerman JL, Ballermann B, Lowenstein Cj. Regulation of endothelial nitric-oxide synthase during hypoxia. J Biol Chem 1996; 21;271:1506973.

38. Hoffman A, Spetner LM, Burke M. Cessation of cell proliferation by adjustment of cell redox potential. J Theor Biol 2001;211:403-7.

39. Palmer LA, Semenza GL, Stoler MH, Johns RA. Hypoxia induces type II NOS gene expression in pulmonary artery endothelial cells via HIF-1. Am J Physiol 1998;274: L212-9.

40. Brüne B, Zhou J. The role of nitric oxide (NO) in stability regulation of hypoxia inducible factor-1alpha (HIF-1alpha). Curr Med Chem 2003;10:845-55.

41. Rouet-Benzineb P, Eddahibi S, Raffestin B, Laplace M, Depond S, Adnot S, Crozatier B. Induction of cardiac nitric oxide synthase 2 in rats exposed to chronic hypoxia. J Mol Cell Cardiol 1999; 31:1697-708.

42. Das S, Alagappan VK, Bagchi D, Sharma HS, Maulik N, Das DK. Coordinated induction of iNOS-VEGF-KDR-eNOS after resveratrol consumption: a potential mechanism for resveratrol preconditioning of the heart. Vascul Pharmacol 2005; 42:281-9.

43. Luss H, Li RK, Shapiro RA, Tzeng E, Mcgowan FX, Yoneyama T, et al. Dedifferentiated human ventricular cardiac myocytes express inducible nitric oxide synthase mRNA but not protein in response to IL-1, TNF, IFNgamma, and LPS.
J Mol Cell Cardiol 1997;29:1153-65.

44. Lohr NL, Keszler A, Pratt P, Bienengraber M, Warltier Dc, Hogg N. Enhancement of nitric oxide release from nitrosyl hemoglobin and nitrosyl myoglobin by red/near infrared radiation: potential role in cardioprotection. J Mol Cell Cardiol 2009;47:25663.

45. Dweik RA, Laskowski D, Abu-Soud HM, Kaneko F, Hutte R, Stuehr DJ, et al. Nitric oxide synthesis in the lung. Regulation by oxygen through a kinetic mechanism. J Clin Invest 1998;101:660-6.

46. Le Cras TD, Mcmurtry IF. Nitric oxide production in the hypoxic lung. Am J Physiol 2001;280:L575-82.

47. Crawford JH, Isbell TS, Huang Z, Shiva S, Chacko BK, Schechter AN, et al. Hypoxia, red blood cells, and nitrite regulate NOdependent hypoxic vasodilation. Blood 2006;107:566-74.

48. Rassaf T, Flögel U, Drexhage C, HendgenCotta U, Kelm M, Schrader J. Nitrite reductase function of deoxymyoglobin: oxygen sensor and regulator of cardiac energetics and function. Circ Res 2007; 100:1749-54.

49. Chen K, Piknova B, Pittman Rn, Schechter AN, Popel AS. Nitric oxide from nitrite reduction by hemoglobin in the plasma and erythrocytes. Nitric Oxide 2008;18:4760 .

50. Vanin AF. Dinitrosyl iron complexes and Snitrosothiols are two possible forms for stabilization and transport of nitric oxide in biological systems. Biochemistry (Mosc) 1998;63:782-93.

51. Mccord JM, Roy RS, Schaffer SW. Free radicals and myocardial ischaemia. The role of xanthine oxidase. Adv Myocardiol 1985; 5:183-9.

52. Haddad IY, Pataki G, Hu P, Galliani C, Beckman JS, Matalon S. Quantitation of nitrotyrosine levels in lung sections of patients and animals with acute lung injury. J Clin Invest 1994;94:2407-13.

53. Balligand JL, Kelly RA, Marsden PA, Smith TW, Michel T. Control of cardiac muscle cell function by an endogenous nitric oxide signaling system. Proc Natl Acad Sci USA 1993;90:347-51.

54. Balligand JL, Cannon PJ. Nitric oxide synthases and cardiac muscle. Arterioscler Thromb Vasc Biol 1997;17:1846-58.

55. Bredt Ds. Nitric oxide signaling specificity-the heart of the problem. J Cell Sci 2003;116:9-15.

56. Massion PB, Balligand JL. Modulation of cardiac contraction, relaxation and rate by the endothelial nitric oxide synthase (eNOS): lessons from genetically modified mice. J Physiol 2003;546:63-75. 